\title{
¿Qué reciben los públicos cuando hablamos de COVID-19?
}

\section{What do audiences hear when we speak about COVID-19?}

\begin{abstract}
FERRER, Argelia ${ }^{1}$
\section{Resumen}

La pandemia de COVID-19 ha copado los medios de comunicación tradicionales y las redes sociales, donde se ha tratado el tema desde distintos ángulos, entre los cuales están el científico y sanitario. Sin embargo, pese a los ríos de información que corren sobre cómo se comporta el coronavirus y las medidas de protección e higiene, la pandemia continúa expandiéndose y cobrando vidas de personas de todas las edades. Ante esta situación, en este ensayo reflexionamos, sin ambiciones de dar respuestas, sobre lo que pudiera estar pasando con esos mensajes y con la disposición de las audiencias a recibirlos y actuar en consecuencia.

Palabras clave: covid-19, comunicación de la ciencia, encuestas de audiencia, estudios de efectos

Abstract

The pandemic of COVID 19 has for a while made the headlines in traditional media as well as social networking sites, all of which approach the issue from different angles, among which the scientific and sanitary points of view can be found. However, in spite of the rivers of information about the behaviour of this coronavirus and the protective easures applied, the pandemic continues to spread and take the lives of people of all ages. In this situation, this essay offers a reflection -without any intention of responding to any questions raised- on what might be happening with all the information available, as well as the willingness of the audience to accept it and act consequently.

Key words: covid-19, science communication, audience surveys, impact analysis
\end{abstract}

\section{Introducción}

Si algún tema copa la agenda informativa de 2020 ha sido sin lugar a dudas la COVID-19. La pandemia ha producido una explosión comunicacional, inundando de material informativo todos los medios de comunicación, tantos convencionales como las redes sociales.

Cuando se habla de comunicación, personal o social, hay elementos que no pueden faltar porque son constitutivos del proceso: el emisor, el mensaje y el destinatario. O como ya lo explicó Aristóteles tres siglos antes de nuestra era: la persona que habla, el discurso que pronuncia y la persona que escucha. En estas líneas pretendemos echar un vistazo a lo que podría estar sucediendo con la recepción de los mensajes sobre la COVID19.

Conjugamos en condicional el verbo poder porque realmente lo que sucede con las audiencias no es asunto que pertenezca al reino de las certezas. Con motivo de la pandemia del 2020, múltiples emisores han puesto a circular múltiples mensajes, de todo tipo, por todos los medios. Ante una amenaza real como el SARS-CoV-2, se han

${ }^{1}$ Universidad de los Andes, Venezuela. argeliaferrer@gmail.com 
generado mensajes disímiles, que van desde la trivialización del tema hasta la voz de alerta para los ciudadanos, desde los gobiernos, los gremios de salud, los organismos internacionales y muchas otras fuentes.

Los mensajes pueden causar efectos diversos y de hecho eso es lo que mueve la maquinaria de la comunicación social. Estos efectos pueden ser informativos, educativos, ideológicos, por nombrar algunos. En el caso de la COVID-19 queremos reflexionar sobre ciertos aspectos que pueden condicionar la manera en que la gente recibe los mensajes que buscan informar a la población sobre qué es, cómo se comporta, cómo se transmite, cómo tratar y cómo prevenir el contagio del coronavirus.

Desde que la COVID-19 comenzó a expandirse, los medios de comunicación no han cesado de hablar del tema y buena parte de sus mensajes han sido para explicar que nos encontramos ante una enfermedad que puede ser mortal, pero que con medidas de higiene y de distanciamiento personal los riesgos del contagio se minimizan. Se supone que esos mensajes deben causar una respuesta que es el acatamiento de los consejos dados. Sin embargo, la realidad nos habla de una expansión incontrolable de casos y de muertes. Por lo que podemos asomar que los mensajes de prevención no han tenido los efectos deseados, al menos en Venezuela, desde donde analizamos algunos aspectos comunicativos de esta pandemia.

\section{Lo que vemos en los medios}

Además de diversos aspectos económicos, políticos y sociales vinculados a la pandemia, el periodismo ha podido llevar a las audiencias otros aspectos relacionados directamente con la ciencia, como las características del coronavirus, su comportamiento, sus formas y mecanismos de transmisión, el desarrollo de pruebas y vacunas para su detección y prevención, así como los tratamientos adecuados para combatirlo.

Esto es tema del periodismo científico (P.C.), que definimos como una especialización que se dedica a la información y análisis de las novedades del mundo de la ciencia, la tecnología y la innovación, a través de los medios de comunicación, que se expresa a través de diferentes géneros y formatos propios del periodismo. Al suministrar informaciones, análisis y opiniones sobre temas vinculados a la ciencia, así como mostrar los distintos puntos de vista que se pueden presentar al respecto, el P.C. cumple una labor informativa, educativa y también puede contribuir a la posibilidad de un debate ciudadano sobre dichos temas. En teoría, por supuesto.

Sobre la COVID-19, en lugar de que los ciudadanos estén mejor documentados, los ríos de noticias, reportajes, opiniones y comentarios de todo tipo se han desbordado, produciendo lo que la Organización Mundial de la Salud (OMS) ha llamado infodemia, que incluye tanto los reportes serios y de fuentes autorizadas, como los que encierran mensajes contradictorios y confusos.

Antes de avanzar queremos precisar el concepto de infodemia, definido por la OMS como "una cantidad excesiva de información sobre un problema que dificulta encontrar una solución. Durante una emergencia de salud (...) pueden difundir errores, desinformación y rumores. También pueden obstaculizar una respuesta efectiva, así como crear confusión y desconfianza en las personas con respecto a las soluciones o los consejos que se plantean para prevenir la enfermedad". (OPS, 2020:2).

Vemos entonces saturación, confusión y excesos que van desde las explicaciones de la pandemia (desde la creación del coronavirus en un laboratorio chino hasta su paso a los humanos por el consumo de algunas especies de animales silvestres); los argumentos (que defienden determinados tratamientos o tomar ciertas infusiones, pasando por la distancia social determinada y hasta la letalidad del microorganismo que para algunos es "una simple gripecita"); las citas (de especialistas que tienen puntos de vistas encontrados, que defienden o alertan sobre el uso de medicamentos, o sobre el desarrollo de determinadas vacunas); la variedad de opciones (vacunarse o no, los distintos tipos de mascarilla, la distancia social recomendada). (Ferrer, 2020a). 
Observamos que el material informativo elaborado con los criterios del periodismo científico compite con un tipo de información muy poderosa, especialmente a través de las redes, por su componente de conflicto. Así encontramos los discursos negacionistas, que rechazan la existencia de la pandemia y la letalidad del coronavirus; de los antivacunas, que ven siempre como sospechosas a las empresas farmacéuticas o asoman el riesgo de controlar por esta vía a la población; o de los conspiranoicos, que atribuyen a componendas políticas las medidas tomadas para el confinamiento, y paremos de contar. $Y$ estos grupos cuentan entre sus filas a políticos, ciudadanos comunes, artistas, médicos y biólogos, por lo cual la confusión está servida en bandeja de plata.

El investigador científico venezolano Alberto Paniz-Mondolfi, virólogo y patólogo molecular que trabaja en el Hospital Monte Sinaí de Nueva York, considera al SARS-CoV-2 como el primer gran virus mediático (de la era de las redes sociales):

Las temporadas de gripe suelen ser bastante severas, pero el virus se puede prevenir porque anualmente se proyecta una vacuna a través de modelamiento molecular. Modelando las cepas que circulan se puede, hasta cierto punto, establecer modelos predictivos del perfil antigénico de la influenza que circulará al año siguiente. Entonces, aunque la influenza causa estragos desde el punto de vista sanitario, se puede prevenir con una vacuna y no causa tanto escándalo. El problema son estos virus emergentes. SARS-CoV-2 fue el primer gran virus mediático en la era de las redes sociales, que sirvieron como amplificadoras del pánico, de la proyección del virus como tal. Las redes sociales son muy importantes y sumamente efectivas pero también pueden ser muy peligrosas porque generan desinformación y han sido uno de los principales vehículos que los movimientos anticiencia y antivacunas han utilizado para lograr permear y llegar a una población largamente ignorante, que es influenciable por esa misma ignorancia y desconocimiento. (Ferrer, 2020b).

Un aspecto que no se puede obviar al analizar el periodismo que se ha hecho sobre la pandemia de COVID-19 es el problema de la credibilidad de las fuentes de información. Al ser un asunto de Estado por sus dimensiones sanitarias, económicas, sociales y políticas, en casi todos los países del mundo han sido los gobiernos $-\mathrm{y}$ en muchos casos las cabezas de gobierno- quienes se constituyen las fuentes principales de la información. Pero para nadie es un secreto que el desencanto de la política y los políticos es generalizado, y quienes por sus cargos e investiduras eran dirigentes - porque efectivamente dirigían la opinión pública - se han convertido en funcionarios en los cuales los ciudadanos han dejado de creer a pie juntillas. Y son ellos quienes se dirigieron a las audiencias desde el primer momento de la expansión del coronavirus para fijar posición sobre temas estrictamente científicos, como el comportamiento del microorganismo, su letalidad y los tratamientos. Y no siempre con tino y cordura.

Paniz-Mondolfi refiere cómo en Estados Unidos la sociedad ha perdido sus referentes morales científicos, y organismos como el Instituto Nacional de Higiene, los Centros de Control de Enfermedades (CDC) y la Administración de Alimentos y Medicamentos (FDA) que controla y regula todo el tema de vacunas, medicinas y alimentos, han colapsado y la gente ha perdido la confianza en ellos, en gran parte por las campañas dirigidas por los movimientos anticiencia y la politización del tema.

En Venezuela - según Paniz Mondolfi- la confianza en las autoridades se ha perdido desde hace muchísimo tiempo, pero la COVID-19 de alguna forma aceleró, catalizó la pérdida de esos referentes morales que existían dentro de la sociedad. Y el sustrato de la pérdida de la confianza tanto en EE.UU. como en Venezuela hacia las instituciones sanitarias y de salud pública es exactamente el mismo: es político. La incapacidad y la mediocridad política, la injerencia de la política partidista en un campo que no le incumbe como es el de la ciencia y la salud pública es 
nefasta y ha causado desconfianza permanente en el sistema de salud pública y en las autoridades sanitarias. Lo mismo ha sucedido prácticamente en todos los países. Pero, como algo positivo, al ocurrir este descalabro de sus referentes institucionales en distintos países, mucha gente empezó a seguir en sus redes a los científicos para buscar respuestas, ese asidero que le diera tranquilidad e información fiable. (Ferrer, 2020a)

Existe un esfuerzo de los científicos para contribuir también, desde el flanco comunicacional, al combate de la pandemia, pero se topa con algunos inconvenientes. Volviendo a Paniz-Mondolfi, el científico afirma que "aunque hay un cuerpo de profesionales que está tratando de informar a la población, de tratar de minimizar el daño ante la orfandad que tenemos a nivel de instituciones sanitarias, no hemos sabido explotar la comunicación científica", no hemos logrado contactar con el ciudadano común para poder dar la información. En Venezuela, algunos profesionales por establecerse como influencers o tener un rol protagónico, opinan sobre lo que no están autorizados por escapar de su área de formación. Si eres un médico cosmetólogo y tienes 7 mil seguidores en Twitter te van a escuchar, pero si eres un virólogo con 200 seguidores, lo que digas no llamará la atención. De ahí la importancia de tener comunicadores de la ciencia en el país. (Ferrer, 2020b).

La incongruencia de las fuentes es otra de las características del manejo de la COVID-19 en algunos países, entre ellos Venezuela, donde las cifras de contagios y decesos suministradas por distintos entes oficiales no son coincidentes (Rodríguez, 2020), ante lo cual los ciudadanos no pueden sino sentir desconcierto.

\section{Qué nos dicen las teorías}

Abarcar todo el proceso de comunicación sobre la pandemia del 2020 es una tarea de dimensiones colosales. En este caso, nuestra mirada está dirigida preferentemente a uno de los elementos del proceso: los receptores de los mensajes, es decir, a las audiencias, a los ciudadanos, así como a los efectos de dichos mensajes, sin que esto signifique que podemos dejar por completo de lado los otros elementos implicados.

La investigación en comunicación se ha ocupado largamente de estudiar a los receptores y los efectos de los mensajes, pues el objetivo de los emisores es que los mensajes lleguen a los destinatarios y produzcan un impacto, bien sea en el conocimiento, en las emociones, en las opiniones, en las actitudes, en las acciones. Precisamos que empleamos indistintamente los términos de receptores, públicos, audiencias o destinatarios en lugar de masas y nos apoyamos en Amparo Huertas, quien explica que el desarrollo de la psicología y la sociología puso en evidencia que las masas están constituidas por públicos diferenciados, que las respuestas a los estímulos de los medios no son homogéneas y que algunas personas, sin ninguna interacción entre sí, presentan reacciones similares (Huertas, 2002:28).

La relación entre las actitudes del receptor y la forma en que este interpreta los mensajes ha sido estudiada por David Berlo, a quien citamos resumido por J. O'Sullivan: "La forma en que [el perceptor] decodifica un mensaje está determinada en cierto modo por sus actitudes hacia sí mismo, hacia la fuente y hacia el contenido del mensaje". Más adelante agrega que "...podemos referirnos al perceptor en términos de su cultura y de su situación dentro de un sistema social. Su propio status social, los componentes de su grupo, sus formas habituales de conducta afectan la manera en que recibe e interpreta los mensajes". (O'Sullivan, 1996:41).

En cuanto a los efectos de los mensajes, se suelen tipificar según el ámbito en que inciden, desde la perspectiva temporal (efectos inmediatos, a mediano plazo y a largo plazo); desde la perspectiva del receptor (individuales, colectivos y sociales); y desde la perspectiva del emisor (efectos intencionados y efectos no previstos). Sobre el ámbito en que inciden, nos interesa destacar:

- Los efectos cognoscitivos (cuestiones sobre la opinión, el saber y los valores aprendidos) 
- Los efectos emocionales (reacciones afectivas, básicamente)

- Los efectos conductuales (o sobre el comportamiento) (Huertas, 2002:84-85).

Los efectos de los mensajes, pues, no están relacionados necesariamente con aquello que los emisores o los medios quieren lograr. La misma autora afirma que "El reconocimiento de que la memoria, la exposición y la percepción son selectivas viene generado por la evolución del estudio de los efectos. Se recuerda lo que más interesa o afecta personalmente, se escuchan los mensajes que resultan más cercanos a las propias creencias y se percibe el contenido en función de las experiencias propias, llegándose incluso a producir decodificaciones aberrantes, contrarias a la intención del emisor". (Huertas 2002:86). Y hay más: algunas investigaciones señalan que apelar al miedo o al peligro puede ser contraproducente si se emplean excesivamente esos recursos pues se generan mecanismos psicológicos defensivos que perjudican la efectividad de los mensajes. (Huertas, 202:88).

La autora, al analizar distintas escuelas que estudian las audiencias, señala los Estudios Culturales, que "alertaban sobre la necesidad de atender al contexto social en el estudio de la recepción" (Huertas, 2002:125), así como los tipos de descodificaciones, o lecturas de los mensajes mediáticos.

En cuanto a los tipos descodificaciones, se señalan la dominante (el receptor descodifica tal como el emisor quiere), la oposicional (el receptor le da al mensaje un significado global contrario a la intención del emisor), y la negociada (el receptor acepta algunos significados del mensaje y se opone a otros). Las variaciones en las maneras que tiene la gente de interpretar los mensajes mediáticos también tienen que ver con los factores sociodemográficos básicos (edad, sexo, raza y clase); la participación en marcos culturales (como sindicatos, partidos, subculturas); la implicación y el conocimientos del receptor sobre el tema; y el contexto de recepción (laboral, educacional o familiar). (Huertas, 2002:129-130).

Por otra parte, la investigadora refiere a Hovland, autor que plantea la existencia de cinco tipos de público: predispuesto a rechazar el contenido, a favor del contenido, con riesgo de recibir contra-argumentaciones, audiencia instruida y audiencia inculta (Huertas, 2002: 77).

Concluimos esta rápida ojeada a algunos aportes teóricos que van más allá de los estudios de audiencias y efectos, como los de Wilbur Schramm sobre las condiciones ideales para que un mensaje llegue a las audiencias, de las cuales destacamos dos: que el mensaje debe despertar necesidades en el destinatario y sugerir algunas maneras de satisfacerlas, pero estas maneras han de adecuarse a la situación del grupo en el que se encuentra el destinatario (O'Sullivan, 1996:32).

\section{4. ¿Qué pasa con la gente?}

Los efectos de los mensajes sobre la COVID-19 son un interesante tema de investigación, sobre todo en función de poder elaborar contenidos más efectivos en esta y en futuras pandemias. Sobre el tema tenemos más preguntas que respuestas.

Recordamos que Berlo afirma que la forma como el perceptor decodifica los mensajes está determinada por sus actitudes hacia sí mismo, hacia la fuente y hacia el contenido del mensaje (O'Sullivan, 1996:41).

En cuanto a las actitudes hacia sí mismo, es posible que la gente se autoperciba como fuerte, con un buen sistema inmune, o se autoperciba como bien informada sobre un tema, pero que en realidad no lo esté lo suficientemente. Eso significa que la gente cree que sabe cómo prevenir el contagio pero realmente no lo sabe, y actúa en consecuencia.

No es lo mismo el conocimiento real y el percibido. Una investigación realizada en Argentina en abril de 2020 indagaba -entre otros muchos aspectos- en la construcción de conocimientos de la población encuestada sobre la COVID-19. "En este sentido, los resultados marcan un mayor conocimiento percibido en comparación al 
conocimiento que realmente tienen las personas (existencia de vacuna y/o tratamiento médico, vías de transmisión del virus, periodo de incubación)." (Villalba, 2000).

En cuanto a las actitudes hacia las fuentes, se ha señalado la existencia de una falta de confianza hacia instituciones o personas quienes deben suministrar la información oficial, tal como lo reseñamos de PanizMondolfi y que se refleja también en una encuesta realizada en España, donde "la respuesta del Gobierno de Pedro Sánchez ante la crisis sanitaria de la COVID-19 divide a la calle, según los datos que arroja el barómetro de mayo del Centro de Investigaciones Sociológicas (CIS). El 48,4\% de los españoles tiene poca o ninguna confianza en el manejo del Ejecutivo, una cifra superior al $46 \%$ con mucha o bastante confianza en Moncloa". (El Periódico, 2000).

¿Están causando efecto los mensajes sobre prevención de la COVID-19? Las informaciones sobre las maneras de evitar la transmisión del coronavirus se hicieron presentes en todos los medios de comunicación y redes sociales desde el inicio de la pandemia, sin embargo, el aumento de casos no cesa en todo el mundo. Luego de meses desde el comienzo del brote, se podría especular que ha habido efectos inmediatos (la toma de conciencia de la vulnerabilidad de algunos grupos, de las medidas de higiene y aseo personal y doméstico, del uso de tapabocas y de distanciamiento social), pero aún se desconoce qué pasará con esos hábitos a mediano y largo plazo.

Este mismo desconocimiento de los efectos de la información sobre la pandemia abarca el impacto temporal, el alcance (individual, colectivo y social) y si los efectos corresponden a las motivaciones de los emisores o no. Tenemos que considerar que los receptores o audiencias reciben informaciones de distintas fuentes y grupos, no solo de los medios, por lo tanto la medición de efectos es compleja. Huertas (2002:84-85) se refería a efectos cognoscitivos - algunos de los cuales ya hemos mencionado al referir los efectos inmediatos- emocionales, como el miedo al contagio; y conductuales.

Si bien los mensajes pueden causar efectos, las investigaciones nos dicen que no están relacionados necesariamente con aquello que los emisores o los medios quieren lograr. Recordamos con Huertas (2002:86) que la memoria, la exposición y la percepción son selectivas: se recuerda lo que más interesa o afecta personalmente, se escuchan los mensajes que resultan más cercanos a las propias creencias y se percibe el contenido en función de las experiencias propias. Como estas experiencias son individuales, difícilmente se puede generalizar sobre los resultados. Pongamos por caso las personas que están en los grupos de riesgo; deberían tener, lógicamente, más interés de prestar atención a las informaciones sobre los cuidados para evitar el contagio. Igualmente, deberían observar con rigor las medidas de prevención. Lo mismo el personal de salud. Sin embargo, el número de contagios y muertes en este último grupo es bastante elevado, por lo menos en Venezuela.

Otro ejemplo muy sencillo sobre las diferencias de percepción basadas en las experiencias: personas que hayan padecido la enfermedad, o algún familiar o amigo haya enfermado o muerto a causa de la misma, tendrán otra relación con los mensajes relacionados que alguien cuyo círculo cercano se haya salvado del contagio.

Se presta atención a los mensajes que resultan más cercanos a las propias creencias. Esto se relaciona con las creencias religiosas, políticas y culturales. Hemos escuchado a personas decir que no necesitan cuidarse tanto porque Dios está a cargo (pero olvidan aquella conseja que recomienda que "A Dios rogando y con el mazo dando"). Las creencias políticas mueven a algunos grupos que manifiestan contra el uso de tapabocas o del distanciamiento social (que hemos visto en los telediarios de España, Estados Unidos y Alemania) porque le atribuyen a esta medida un cariz represivo. Lo mismo ocurre en Venezuela. Las creencias culturales son mucho más complejas y tienen que ver con prácticas y experiencias cotidianas que llevan a las personas a desoír consejos de prevención. Como ejemplos están el creer que consumiendo infusiones de determinadas plantas se ataca el 
virus, como si fuera una gripe cualquiera, o prácticas en sitios públicos de personas compartiendo tragos de aguardiente de la misma botella, por la creencia de que "el alcohol lo mata todo".

Otro de los aspectos interesantes para investigar es el tipo de decodificación preferente sobre los mensajes vinculados a los aspectos científicos y sanitarios del coronavirus SARS-Cov-2. Huertas (2002:129-130) se refiere a la decodificación dominante (el receptor descodifica tal como el emisor quiere), la oposicional (el receptor le da al mensaje un significado global contrario a la intención del emisor) y la negociada (el receptor acepta algunos significados del mensaje y se opone a otros). Pero la interpretación de los mensajes mediáticos también tiene que ver con los factores sociodemográficos básicos (edad, sexo, raza y clase); la participación en marcos culturales (como sindicatos, partidos, subculturas); la implicación y el conocimiento del receptor sobre el tema; y el contexto de recepción (laboral, educacional o familiar).

Para ilustrar las diferencias en los tipos de decodificación podemos emplear el ejemplo del aviso gubernamental de la llegada de la vacuna rusa del laboratorio Gamaleya a Venezuela, el 2 de octubre, junto a la información de que una hermana y el hijo del presidente Nicolás Maduro se la aplicarían. Ya previamente, con fecha 24 de agosto, la Sociedad Venezolana de Puericultura y Pediatría había hecho público un comunicado alertando a la población sobre la inconveniencia de utilizarla por no estar precalificada por la Organización Mundial de la Salud. Las noticias sobre un avance científico, teñidas de política, pueden llevar a las audiencias a aceptar la vacuna, rechazarla, o aceptar una vacuna contra la COVID-19 mientras no sea la rusa. La aceptación o no de la vacuna dependerá de las informaciones y de la interpretación que las audiencias les den según su pertenencia a determinados marcos culturales, como la tendencia política y el contexto de recepción.

Todo este caudal informativo es procesado de distintas maneras por las audiencias, y así como encontramos a quienes no convencen las informaciones sobre la gravedad de la pandemia, también hay grupos que aceptan como cierto lo que los negacionistas, los antivacunas o los conspiranoicos proponen. Si la COVID-19 es "una gripecita", se puede muy bien curar con hierbas, o no tiene mayor peligro si hay contagio, o no hay que cuidarse tanto porque lo que quieren los gobernantes es tener a la gente encerrada en casa para que no proteste, por ejemplo.

Por otra parte, el tema se ha banalizado o estructurado para causar temor. Los discursos mediáticos sobre los aspectos de salud del coronavirus oscilan entre la banalización de los efectos del contagio de COVID-19, por parte de algunas personalidades públicas, hasta la siembra de miedo como recurso propagandístico. Los dos extremos son peligrosos. Recordamos a Huertas (202:88) quien refiere algunas investigaciones donde se señala que apelar al miedo o al peligro puede ser contraproducente si se emplean excesivamente esos recursos, pues se generan mecanismos psicológicos defensivos que perjudican la efectividad de los mensajes. A esto le sumamos la consecuencia de la infodemia, que llena al ciudadano de confusión, o lo satura a tal punto que ya no quiere saber más sobre un tema que lleva demasiados meses copando los telediarios, los periódicos, las redes.

Los receptores interpretan las informaciones y actúan según sus creencias por los contenidos mismos de los mensajes, pero también por sus características individuales. Como señalamos, Hovland (en Huertas, 2002:77) plantea la existencia de cinco tipos de público: predispuesto a rechazar el contenido, a favor del contenido, con riesgo de recibir contra-argumentaciones, audiencia instruida y audiencia inculta. La falta de cultura científica en nuestras sociedades - solo combatible con educación e información de calidad, y que es una de las motivaciones de la comunicación de la ciencia - es campo propicio para que las informaciones sobre la pandemia tengan efecto o no en las audiencias.

No podemos pasar por alto que existen unas condiciones ideales para que un mensaje llegue a las audiencias, estudiadas por Schramm (en O'Sullivan, 1996:32) de las cuales destacamos dos: que el mensaje debe despertar necesidades en el destinatario y sugerir algunas maneras de satisfacerlas, pero estas maneras han de adecuarse 
a la situación del grupo en el que se encuentra el destinatario. Muchos de los mensajes sobre la COVID-19 despiertan necesidades en los públicos, como protegerse y proteger a sus familiares o cambiar hábitos personales y sociales, pero el problema surge muchas veces en las maneras de satisfacer esas necesidades. En el caso de Venezuela, para muchos no es fácil lavarse frecuentemente las manos, cuando hay amplísimos sectores que carecen de agua potable y los baños públicos son prácticamente inexistentes; o utilizar gel alcoholado, cuando el costo del mismo y del alcohol es mayor que un salario mínimo; o guardar el distanciamiento social, cuando el hacinamiento en viviendas y transporte público es cotidiano y generalizado. La utilización de tapabocas específico se compensa con los manufacturados en los hogares (muchas veces con telas inadecuadas), pero en general, amplias capas de la población están muy limitadas, aunque quisieran, para seguir las recomendaciones para evitar el contagio del coronavirus.

\section{Más allá de la comunicación}

Los ciudadanos necesitan información confiable para tomar decisiones y actuar en consecuencia. Esa información debe estar elaborada con conocimiento de lo que la gente -esos públicos destinatarios de los mensajes- sabe, siente y cree. Los comunicadores deben estar conscientes de que dichos mensajes producen efectos, que aunque no sean los deseados por los emisores, mueven a la gente a actuar o a dejar de hacerlo.

En tiempos de pandemia, el periodismo científico está llamado a tratar los temas de ciencia y salud con precisión, claridad, independencia, honradez, integridad, así como con rigor, exactitud, veracidad, competencia, ética y responsabilidad. Sin embargo, nos queda siempre una inquietud sobre el alcance que pueda tener la información, por muy bien elaborada que esté, si la población carece de las herramientas - producto de una educación de calidad - para recibir, procesar y analizar los mensajes científicos y de salud sobre la pandemia de COVID-19. No se puede pasar por alto que las personas tienen prejuicios sobre las enfermedades y sus causas, sobre la ciencia, sobre los medios y los periodistas y sobre los gobernantes y sus intenciones (Ferrer, 2020a). Adicionalmente, muchos de los destinatarios de los mensajes tienen condiciones socioeconómicas que les impiden, aunque lo quisieran, responder adecuadamente a lo que se les pide como población para cuidarse y evitar la propagación de la enfermedad.

Quienes elaboran y difunden mensajes relacionados con la COVID-19, su comportamiento, la prevención, sus efectos, el tratamiento y todos los aspectos sanitarios y científicos del coronavirus, si quieren llegar a los destinatarios con efectividad, tienen que tomar en cuenta que los públicos o audiencias tienen características individuales, pertenecen a diferentes grupos sociales y culturales y descifran e interpretan de maneras distintas lo que se les dice por los medios de distintas maneras. Y que lo que se quiere transmitir no necesariamente es lo mismo que entienden los públicos cuando se les informa sobre la COVID-19.

\section{Referencias}

El Periódico (2000) Encuesta CIS: la respuesta del Gobierno ante la crisis del coronavirus divide a los españoles. Recuperado de https://www.elperiodico.com/es/politica/20200519/cis-barometro-mayo-encuestacoronavirus-tezanos-congreso-7966934

Ferrer, A. (2020a) Periodismo Científico en tiempos de pandemia. Recuperado de: https://fakenews.cotejo.info/en-profundidad/periodismo-cientifico-en -tiempos-de-pandemia-parte-2/

Ferrer, A. (2020b) Entrevista inédita realizada al Dr. Alberto Paniz Mondolfi vía Wathsapp, de 1 al 3 de septiembre de 2020.

Huertas, A. (2002). La audiencia investigada. Barcelona, Gedisa. 
O.P.S. Organización Panamericana de la Salud (2020). COVID-19. Consejos para informar. Guía para periodistas. Recuperado de https://www.paho.org/es/documentos/covid-19-consejos-para-informar-guia-paraperiodistas.

O’Sullivan, J. (1986). La Comunicación Humana. Grandes temas contemporáneos de la comunicación. Caracas. Universidad Católica Andrés Bello/ Fondo de Publicaciones Fundación Polar-UCAB.

Rodríguez, M.F. (2020). En 17 estados de Venezuela las cifras COVID-19 difieren del registro nacional. Recuperado de https//elpitazo.net/salud/en-17-estados-de-venezuela.las cifras.covid.19-difieren.del registro-nacional/.

Villalba, M.J. (2020) Casi la mitad de los argentinos considera improbable que vaya a contraer coronavirus. Recuperado en https://uniciencia.unc.edu.ar/sociedad/casi-la-mitad-de-los-argentinos-consideraimprobable-que-vaya-a-contraer-coronavirus/ [8/4/2020] . 1 de octubre de 2020.

Esta obra está bajo una Licencia Creative Commons Attribución-NoCommercial 4.0 International

(cc) EY-NC 